\title{
3. A vast improvement: the 2006 enumeration in the Alice Springs town camps
}

\section{Will Sanders}

\section{Introduction}

The conduct of the 2006 Census in the Alice Springs town camps was a vast improvement on 2001. Later I will suggest some reasons for this, as well as identifying some remaining issues. I will begin, however, by recalling some of the major problems of the 2001 collection process and identifying developments since. I will then tell the story of the 2006 collection in the Alice Springs town camps, as I observed it. This should lay some foundations for understanding more analytically in the later sections of the chapter how and why the 2006 Census collection process in the Alice Springs town camps was such a vast improvement on 2001.

\section{1 remembered and developments since}

My analysis of the collection of the 2001 Census in the 19 Alice Springs town camps pointed to the overwhelming demands of the task (Sanders 2002). The household plus personal form structure used in 2001 was extremely cumbersome and quickly wore out interviewers and interviewees. About 25 collector-interviewers (CIs) were employed during a four to five-week period in 2001, with many lasting only a day or two, or a camp or two, before quietly slipping away. The Community Coordinators (CCs) in 2001 had to salvage the situation by giving up on the personal forms about 12 days into the collection process. From then on they focused just on the household forms, augmented slightly with a few hand-ruled columns.

Another inadequacy in 2001 was that visitors in the camps were not being counted. The assumption was that they would be counted elsewhere as absent usual residents. As an observer, I was dubious of this idea. As well as short-term visitors who might possibly be counted elsewhere, the term 'visitor' seemed to cover some quite long-term residents of town camps who were still distinguished from the recognised tenants of houses or owners of camps. I judged that the likelihood of these long-term visitors being counted elsewhere was very slight. In addition, not counting visitors did nothing to demonstrate the demands these people placed on town camp services, which was an important issue for the town camp servicing organisation, Tangentyere Council. Any attempt to count visitors in the town camps in 2001 would, however, have only added to the 
overwhelming demands of the census task, so it was perhaps just as well that this was not attempted.

The results of the 2001 Census, released in 2003, showed the Alice Springs town camps had 973 residents in 189 dwellings or households (Sanders 2004). Tangentyere was dissatisfied with these figures because they did not include visitors but also because they thought this was a significant under-count of residents. It was partly this dissatisfaction with the 2001 Census that spurred Tangentyere to develop its own population and mobility study in 2004 and 2005 (Foster et al. 2005). This study surveyed the town camps four times from mid 2004 to mid 2005, finding at various times between 906 people in 151 dwellings and 1341 people in 195 dwellings (see Table 3.1). These surveys demonstrated that between 16 and 21 per cent of the people counted in the town camps at these various time were visitors. They also led to the compilation of a cumulative list of 2326 named people counted in 255 dwellings in the 19 camps during the course of the year. This study was therefore beginning to show how Tangentyere had a significantly larger service population in the town camps over a year than the resident population at any one time, including visitors.

Table 3.1 Results of Tangentyere population and mobility surveys

\begin{tabular}{llll}
\hline & Dwellings surveyed & People counted & Proportion visitors \\
\hline June 2004 & 151 & 906 & 0.21 \\
Oct 2004 & 202 & 1205 & 0.20 \\
Apr 2005 & 177 & 1111 & 0.16 \\
June 2005 & 195 & 1341 & 0.17 \\
\hline
\end{tabular}

Through these and other research efforts, Tangentyere had by 2005 developed a strong research unit of its own. In late 2005, the Tangentyere research unit was asked by the Australian Bureau of Statistics (ABS) to conduct a trial of the new Interviewer Household Form (IHF) for the 2006 Census in one of the town camps. This they did with a combination of enthusiasm and trepidation. The Tangentyere researchers were interested in the census, but were reminded through the trial of the size of the census task and its demanding nature. They were also beginning to realise how the census might potentially crowd out their own research opportunities. I will return to this later, but will conclude here by arguing that in 2006 Tangentyere was far better prepared and positioned for the coming of the census than in 2001.

\section{Collecting in 2006}

Planning and negotiations between the ABS and Tangentyere for the collection of the 2006 Census in the town camps began quite early in the year. The ABS opened an Alice Springs office in March-compared with somewhat later in 2001. By the time I visited in May, there had already been discussions and developments regarding the ABS supplying cars so collectors could move between Tangentyere's central office complex and the camps scattered across Alice Springs 
(see Figure 3.1). There had also been negotiations about working and being paid in teams of two, as was the practice in the Tangentyere population and mobility surveys.

Fig. 3.1 The Alice Springs town camps (Community Living Areas)




By the time I returned on Monday 17 July - three weeks and one day out from the general census night on Tuesday 8 August - the Census Field Officer (CFO) had conducted training of eight CIs late the previous week and the first day of collecting in the town camps was under way. All the CIs were Aboriginal women, some of whom lived in the town camps themselves, but most of whom lived in other housing around town. In the next day or so, another two or three CIs were added, still all women, though there was some consciousness at the time of trying to recruit some men. The new CIs who had missed the formal training of the previous week were effectively trained by giving them a DVD to watch and by pairing them with established CIs, who by then had a day or two's experience. One or two CIs pulled back after their first encounter with the hard reality of collection. Most, however, stayed with the task, while also clearly realising that it was not always going to be easy. There were also a few teething troubles in those first few days over the numbering of dwellings in the camps on the green Interviewer Dwelling Checklist (IDC). There was an initial attempt to use a different dwelling numbering system to Tangentyere's existing house-numbering system. It soon became evident, however, that it was clearer to use the existing Tangentyere system and then to add as necessary any other occupied dwellings, such as tin sheds or community facilities.

The collection process settled during its first week into a pattern of about eight women CIs assembling at the Tangentyere research unit office about 8.30am and, under the supervision of the CFO, dividing into two or three car-loads of teams. A car-load of collectors would focus on one of the 11 groupings of town camps that corresponded with an ABS Collection District (CD). Generally, two such CDs of camps were being worked on at a time by different teams of CIs. Out in the camps, the women approached a dwelling and asked for the house boss'. If the house boss was available, the interview generally took place then and there; if not, an attempt was made to identify a time to come back. Occasionally, someone present was identified who was not the house boss but who had sufficient knowledge and authority within the household group to answer on their behalf. Another possibility was to meet the house boss elsewhere - for example, at their work. Local knowledge proved important here, since most of the CIs seemed to know most of the house bosses, even if only vaguely, and when and where they might be found if they were not home on the first visit.

Interviews could take anywhere between 40 minutes and an hour, depending largely on the number of people in the household. Teams of two CIs could generally complete between three and four household interviews in a morning, depending on whether they stuck together closely as a team of two or split up as opportunities for interviews developed. Teams of CIs would regroup at the Tangentyere research office for lunch and to transfer details from the pink IHFs to their green IDC. Dwellings were being dealt with at a rate of about 12 a 
morning and then, in the afternoon, through follow-up, at a rate of perhaps another three or four. Mornings were therefore the main work period, followed by a considerably less concerted work period after lunch.

Within interviews, the first half of the 40 to 60 -minute process would be spent answering the opening questions about the dwelling and listing people who were either living in or staying in the dwelling now (Question 12; see Appendix A) or who lived there most of the time but were away (Questions 10 and 11). These questions also covered the basic age and gender characteristics of each person listed, and also whether they were a visitor, or their location if they were away. Once this listing of people's names, ages and genders was complete, interviews settled into a somewhat more routine mode of answering questions about the people listed in Question 12 as living or staying there now. Interviewers generally answered each question for each person listed before moving on to the next question. This 'vertical' working method had been anticipated during form design as the likely dominant mode of collector operation and certainly this proved to be the case in the Alice Springs town camps.

This process of enumeration of about 12 to 15 dwellings a day continued from Monday to Thursday in the first week of the collection process under the supervision of the CFO. Friday was seen as a day off, as is commonly the case in Aboriginal communities, particularly where employment is through the Community Development Employment Projects (CDEP) scheme. During this first week it also gradually became understood more clearly that in the second week, the $\mathrm{CFO}$ would be attending to collection processes out of Alice Springs and hence would not be around. The CIs, one of whom was also now designated as the $\mathrm{CC}$, would therefore be a little more on their own. It was also understood, however, that with the absence of the CFO the District Manager and her Assistant would endeavour to provide daily support, at least at the Tangentyere research office if not out in the camps. Perhaps their most important form of daily support was providing lunches, which were proving a useful social and administrative focus for the group of CIs as they returned to the Tangentyere research unit office after their morning's work.

The second week of the collection process proceeded, in fact, much like the first. The group of women CIs seemed to have developed a fairly good camaraderie and, apart from some occasional absences to attend to other life matters, the team of eight or so CIs hung together well. By the end of the second week, at least a first attempt had been made to carry out the collection in eight of the 11 town camp Collection Districts. Three of perhaps the largest and most difficult town camps remained to be tackled, as well as many follow-ups of dwellings in the other town camps in which the house boss had not been available for interview at the first or even second visit. Progress with the count was, however, generally 
seen to be good and two of the women CIs decided to take opportunities to accompany CFOs to the bush the next week as Assistant CFOs.

The third week of the census collection process in the town camps therefore began with a slightly reduced team. As well as the two CIs now out bush, another CI pulled back because she had lost her working partner and a fourth, reportedly, pulled back due to concerns that earning too much might adversely effect her Centrelink entitlements. One or two of the other CIs told me that this was not a concern for them as they were on CDEP, which had more relaxed and generous provisions for earning additional income than Centrelink payments. Therefore, only about five or six CIs were left for this third week, and there was a sense in which the collection process in the town camps was now winding down. There were, however, still two quite large camps to count, which had been left to last in part because they were seen as perhaps the most difficult and possibly disrupted by large numbers of current visitors or other recent events - including some 'sorry business' and fighting. In the event, four male Tangentyere housing workers were coopted to assist the women in approaching dwellings in the last three camps. Although I did not directly observe the difference this made, it was reported by those involved as making a significant contribution to a difficult final task. By the end of this third week, the task of collecting the 2006 Census in the Alice Springs town camps was seen as essentially done. Most of the women collectors had had enough and were happy to finish, however, the woman who had been doing some CC tasks stayed on for a couple of days, crosschecking IHFs with IDCs and Master Dwelling Checklists (MDCs).

This crosschecking of forms showed that roughly 1200 people had been counted as present in the town camps in about 190 households. Hence, what had taken four or five weeks with 25 CIs in 2001, resulting in a salvage operation and no counting of visitors, had been achieved in 2006 in three weeks in a planned and orderly fashion with eight to 10 CIs and included visitors. So why, one might ask, was there such a vast improvement?

\section{Reasons for improvement}

The single most important reason for the improvement, it seems to me, was the new IHF. Although physically a little cumbersome, as an administrative system for enumerating people associated with a dwelling, the new form worked well. It was far less cumbersome and demanding than the previous system of household and personal forms. Under the old system, the collection task had only just begun at the point where people associated with a dwelling had been listed. A vast task of attempting to fill in personal forms for each person listed then still lay ahead. With the new IHF, once the people associated with a dwelling had been listed at Questions 10-12, together with their gender and age, the collection task was about half complete. What lay ahead was a more routine process of answering substantive questions about the people listed predominantly by 
putting marks in boxes and occasionally doing a bit of writing. This was far less demanding than the daunting task of separate personal forms required in 2001. Another reason for improvement - specific to the Alice Springs town camps in 2006 - was that Tangentyere was far better tied into the ABS than in 2001. The research unit in Tangentyere provided a focus for forward planning and negotiation for the ABS, which had not been there in 2001. Issues such as the need for cars, working in pairs and being paid in pairs were negotiated well in advance. This laid the foundations for an orderly collection process that, although still demanding for CIs, was realistic and achievable. That the CIs could use the Tangentyere research unit office as their operational and social base was also particularly important, even though, in the end, the group of CIs recruited included only three people who had been involved directly in the Tangentyere population and mobility study. There were also two employees of the Tangentyere research unit operating in the background who had been involved in the population and mobility study and who were supporting the CIs and the $\mathrm{CC}$, even though they were not themselves employed directly by the ABS. In a number of different ways therefore the Tangentyere research unit provided an enormous base of strength and support for the 2006 Census collection process and personnel.

A third reason for improvement was that the ABS committed more of its staff time to the Alice Springs town camps in 2006 compared with 2001. In 2001, the District Manager had acted effectively as CFO for the town camps, squeezing his involvement between other commitments. In 2006, the town camp collection process had the full-time attention of a CFO for a week and a half in order to get training done and the count substantially under way, before he went off to do similar work out bush. After the CFO had moved on, the District Manager and her Assistant took a continuing monitoring and support role for the next two weeks. I would say that, compared with 2001, the level of ABS staff attention and support for Tangentyere and the town camp collection process was probably about double.

A fourth minor reason for improvement was possibly also the greater engagement of the Northern Territory government in 2006. This was partly because the Territory had almost lost a House of Representatives seat in 2003 on the basis of the 2001 Census count (Joint Standing Committee on Electoral Matters 2003). It was also because the recommendations of the Commonwealth Grants Commission for general revenue sharing relied heavily on population numbers and the Northern Territory government believed it might be missing out here as well. Indeed, in the lead-up to the 2006 Census, the government ran a newspaper advertising campaign under the slogan 'We're counting on you', in which Chief Minister, Clare Martin, explicitly made the link between the numbers of 'Territorians counted' and 'the amount of money we receive from the 
Australian government' (see, for example, Centralian Advocate 2006). The Northern Territory government also directed its employees to be as helpful as they could to the census process. At the regional office level, this led to the ABS's temporary administration in Alice Springs being co-located with the Territory government's Department of Local Government, Housing and Sport, which through its field staff could provide intelligence on situations and service personnel in various Aboriginal communities. My intuition is that these intergovernmental links probably contributed more to improving the census collection process in outlying areas than in the Alice Springs town camps, where the ABS had well-established, direct relations with Tangentyere and did not need to rely on government connections and intelligence.

\section{Remaining issues}

There are some issues remaining with the design and content of the IHF; these are addressed in Appendix B. One final issue relates to visitors. The Tangentyere research unit found in its population and mobility study that it was hard to distinguish between residents and visitors. They had a 'long discussion' about the issue when designing their survey, including the possibility of defining visitors by 'how long they had been staying there' (Foster et al. 2005: 16). In the end, the Tangentyere research unit decided to let the 'house boss' for each dwelling tell them who was a resident and who was a visitor. They found that there were a significant number of visitors who had been staying at dwellings for longer than six weeks, or even longer than three months. They commented, after noting this, that it seemed that who is a visitor is related to the right to be at [a] particular camp or dwelling' (Foster et al. 2005: 16).

This finding bears out emphatically the inadequacy of the 2001 approach of leaving visitors in the town camps to be counted elsewhere, and the correctness of the 2006 Census approach of trying to count visitors. When such long-term residents are referred to as visitors, however, the question arises as to whether very short-term visitors are also being captured by this terminology. This issue can also be approached by reflecting on another finding of the Tangentyere population and mobility study.

The third survey in the Tangentyere study in April 2005 was carried out during two weeks straddling a major weekend football carnival. The Tangentyere research unit expected that this might lead to higher numbers of visitors in the camps than in their first two surveys; however, with a line of questioning that focused explicitly on who stayed in a dwelling 'last night' they still did not seem to be able to capture this short-term visitation. They commented of their third survey: 'The football visitors were not at the camps after the weekend, and there was not a significantly higher number of visitors. It seemed that most of the football visitors came in for the weekend only and went back to their communities straight away' (Foster et al. 2005: 19). 
With Tangentyere unable to capture this expected short-term visitation in its survey, it is perhaps to be expected that the census might have similar problems. Question 12 on the IHF did not go quite so far as saying that everyone should be listed who stayed at a dwelling last night; rather it opted for the slightly more general terminology of people 'who are living or staying here now'. It is possible therefore that the census collectors in 2006 missed overnight visitors to town camps in much the same way as the football visitors were missed by the Tangentyere research unit survey in April 2005. This is not a problem for the census as a whole, since such short-term visitors to the town camps are reasonably likely to be counted elsewhere. It simply means that the visitor count at Tangentyere, while capturing longer-term visitors, might still not capture fully very short-term visitors.

\section{Tangentyere's list}

One final interesting aspect of the 2006 Census collection process in the Alice Springs town camps was some discussion that occurred between Tangentyere and the ABS about the possible use of Tangentyere's list of 2326 named people present in town camps between June 2004 and June 2005. There was some suggestion that this list might help collectors locate people or act as a form of validation of those counted; however, in the end, the list was not used during the collection process.

Tangentyere's interest in using the list was partly also a wish to update it, as it was by census time more than a year out of date. Tangentyere saw the census as occupying some of its available research time and opportunity in the camps, and hoped that the ABS might see its way clear to allow them to use the census to update their list as a quid pro quo. As it became clear that the ABS could not under any circumstance allow personal information collected in the census to be transferred to some other database, Tangentyere became somewhat less interested in making their list of names available to the ABS.

In the past, there have often been suggestions that existing lists generated by administration of other processes could in some way lessen the demands of the census on Aboriginal communities and increase its reliability (for example, Martin and Taylor 1996). I have never been as convinced of this argument as some others, feeling that lists are generated for particular purposes at particular times and are often of limited use beyond those particular purposes and times. One issue raised by this example of the non-use of Tangentyere's list is that the owners of those lists will often want something in return for their use and the ABS has extreme difficulty offering anything. I do not believe that the use of the Tangentyere list would have greatly changed the collection of the 2006 Census in the Alice Springs town camps. I suspect that the majority of the 1200 people enumerated as present in the town camps in July and August 2006 were on Tangentyere's list of 2326 named people from 2004 and 2005. The people 
who were present in the town camps did in the end seem to be able to be identified reasonably readily. What the list would have added would have been as many names again of people who could have been asked about. Most of these people would probably have been identified as not currently living in the camps. A few might have then been remembered as living there but were away, or even living there but forgotten - which could have increased the count a little. To pick up this last category of genuinely missed people, it would have been quite a lot of work to go through more than 1300 additional names.

Ten months on, the ABS compared the census counts in four camps with Tangentyere's survey of 4 August 2005 to see whether there were any significant differences in numbers of people enumerated by age structure or number of dwellings. This was a very modest validation exercise in contrast with some of the early ideas for the use of Tangentyere's list.

The vast improvement of the 2006 Census on the 2001 Census in the Alice Springs town camps lay in the fact that it reduced the collection task to a reasonably simple and manageable administrative procedure. Any attempt to use Tangentyere's list as an adjunct to the collection process would, in my judgment, have added to the complexity of the task without greatly enhancing the ability of the CIs to find people. The CIs were successful because they had a familiarity with the town camp environment and were well supported by Tangentyere and the ABS. What Tangentyere's list could have added to this success was marginal at best.

\section{Conclusion}

In conclusion, I would simply return to and reiterate three of the reasons for improvement from the 2001 Census identified above. The first of these was the redesign of the household and personal forms into the single, integrated IHF. Although still not perfect-and still quite demanding on interviewers and interviewees - this new form did at least give CIs a task that was possible. This was not the case in 2001 .

Beyond this general improvement, the second factor was a specific improvement in relations between the town camp servicing organisation, Tangentyere Council, and the ABS. Tangentyere's own research capacity had grown significantly since 2001, partly as a result of its dissatisfaction with the results of the 2001 Census. Because of this, Tangentyere was more interested in the census in 2006 and more assertive in its relationship with the ABS. Tangentyere could now draw on its own experience of doing surveys in the town camps and knew the difficulties and the requirements of doing so. For the ABS-perhaps somewhat unusually-Tangentyere was now a highly engaged and quite experienced Indigenous partner organisation. This was no doubt at times somewhat challenging and uncomfortable for the ABS, but it laid the basis for an orderly 
and achievable census collection procedure in the town camps in 2006. Tangentyere negotiated with the ABS about committing resources adequate to the task - in personnel and in other costs such as cars - and the ABS responded. This level of commitment of ABS resources was the third factor behind the vast improvement from 2001. To what extent this level of commitment of ABS resources was different from, and possibly even at the expense of, other Indigenous communities with less-engaged service organisations could throw some light on the rather less orderly accounts of the 2006 Census collection process that my colleagues report (Chapters 4-6). While the Alice Springs town camps were seen by some within the ABS in 2001 as possibly a 'worst-case scenario' (Sanders 2002: 88), in 2006, they might well come to be seen as more of an example of best practice, which the ABS will aim to repeat in the future and emulate elsewhere. 